\title{
Thermal Aging of Melt-Spun NdFeB Magnetic Powder in Hydrogen
}

\author{
Frederick E. Pinkerton, ${ }^{1, *}$ Michael P. Balogh, ${ }^{1}$ Nicole Ellison, ${ }^{1}$ Aldo Foto, ${ }^{2}$ Martin Sechan, ${ }^{3}$ Misle M. \\ Tessema, ${ }^{3}$ and Margarita P. Thompson ${ }^{3}$ \\ ${ }^{1}$ Chemical and Materials Systems Laboratory, General Motors Research and Development Center, \\ Warren, MI 48092 \\ ${ }^{2}$ Element Materials Technology Wixom, Inc. \\ ${ }^{3}$ Powertrain Materials/Fluids/AMPPD Engineering and Labs, GFL VE/PT Materials Engineering, \\ General Motors LLC, Pontiac, MI 48340
}

*Corresponding author: frederick.e.pinkerton@gm.com

\begin{abstract}
High energy product neodymium-iron-boron $(\mathrm{NdFeB})$ magnets are the premier candidate for demanding electrified vehicle traction motor applications. Injection molded (IM) or compression molded (CM) magnets made using NdFeB powders are promising routes to improve motor efficiency, cost, and manufacturability. However, IM and CM NdFeB magnets are susceptible to substantial thermal aging losses at motor operating temperatures when exposed to the automatic transmission fluid (ATF) used as a lubricant and cooling medium. The intrinsic coercivity $\mathrm{H}_{\mathrm{ci}}$ of NdFeB IM and CM magnets degrades by as much as $18 \%$ when aged for $1000 \mathrm{hr}$ in ATF at 150 ${ }^{\circ} \mathrm{C}$, compared to a $3 \%$ loss when aged in air. Here we report aging studies of rapidly quenched $\mathrm{NdFeB}$ powder in air, ATF, and $\mathrm{H}_{2}$ gas. Expansion of the NdFeB crystal lattice in both ATF and $\mathrm{H}_{2}$ identified hydrogen dissociated from the ATF during aging and diffused into the primary $\mathrm{NdFeB}$ phase as the probable cause of the coercivity loss of IM and CM magnets.
\end{abstract}

Keywords: Permanent magnets; neodymium-iron-boron; thermal aging; melt-spun; injection molding 


\section{INTRODUCTION}

Permanent magnets are a critical component of high performance traction motors used in vehicle electrification. High energy product sintered neodymium-iron-boron (NdFeB) magnets are the premier candidate for these demanding applications, however preventing demagnetization at operating temperatures near $150{ }^{\circ} \mathrm{C}$ requires that the magnets be doped with dysprosium (Dy) or Terbium (Tb), at a substantial cost penalty. Furthermore, the sintered magnet manufacturing process is economically feasible only for rectangular cross-section magnet segments. Injection molded (IM) or compression molded (CM) magnets made using NdFeB powder, for example isotropic melt-spun $\mathrm{NdFeB}$ powder, are promising routes to improve motor efficiency and reduce cost through greater motor design flexibility. The magnetic powder and a polymer bonding agent are directly injected into the rotor magnet slots, resulting in a composite magnet with about a $50 \%$ volume fill fraction of $\mathrm{NdFeB}$ powder.

The traction motor design is integral with the transmission, thus both for transmission lubrication and to cool the traction motor, the motor is exposed to flowing automatic transmission fluid (ATF). We have evaluated the aging properties of IM and CM magnets in ATF at $150{ }^{\circ} \mathrm{C}$ for exposures up to $2000 \mathrm{hr}$, and found substantial aging losses. Furthermore, the aging losses were generally worse in ATF than those of the same magnets aged at $150{ }^{\circ} \mathrm{C}$ in air. As detailed here, examination of the magnet and ATF chemistry after aging showed that the aging was not due to chemical reaction of the $\mathrm{NdFeB}$ with elements such as carbon or sulfur present in the ATF. Aging of NdFeB powders without a bonding agent generated similar aging characteristics, demonstrating that reaction between $\mathrm{NdFeB}$ and the binder was not the primary aging mechanism.

Here we report the effect of aging melt-spun NdFeB powder in hydrogen gas at $150{ }^{\circ} \mathrm{C}$. Hydrogen is suspected in the deterioration of magnetic properties because it is a prevalent element in ATF that could potentially dissociate from the liquid ATF, and because hydrogen absorption is known to produce changes in the structural and magnetic properties of NdFeB. We find that aging in hydrogen gas greatly accelerates the degradation of $\mathrm{NdFeB}$, accompanied by crystal lattice expansion of the primary $\mathrm{Nd}_{2} \mathrm{Fe}_{14} \mathrm{~B}$ phase due to hydrogen diffusion into the $\mathrm{Nd}_{2} \mathrm{Fe}_{14} \mathrm{~B}$. Our results strongly suggest that hydrogen is indeed a major contributor to thermal aging of melt-spun NdFeB powder. 


\section{EXPERIMENTAL DETAILS}

Melt-spun NdFeB powder was injection molded by outside vendors to form $1 \mathrm{~cm}$ cubes or 1 $\mathrm{cm}$ diameter $\times 1 \mathrm{~cm}$ high cylinders using nylon or polyphenylene sulfide (PPS) as the binding agent. CM magnets were made using an Epon epoxy binder. The magnets were aged at $150{ }^{\circ} \mathrm{C}$ in air or by immersion in ATF for up to $2000 \mathrm{hr}$. Magnets were removed at 72, 500, 1000, and $2000 \mathrm{hr}$ and the demagnetization curves of pulse magnetized magnets were measured using a HG-700 Hysteresisgraph from Magnetic Instrumentation Inc., KJS Associates.

Powders of melt-spun NdFeB were similarly aged in air or ATF utilizing a Scott Oven. The ATF-aged powders were shaken once per week to maximize exposure to the fluid. Upon completion of each ATF aging interval, the ATF was collected in a retain bottle and the powders were rinsed with hexane. The hexane rinse was repeated four times and the powders were then dried at $85^{\circ} \mathrm{C}$ for 1 hour. The same volume of ATF (for each respective test vial) was reused throughout the $2000 \mathrm{hr}$ aging process. Demagnetization curves on pulse magnetized powders were measured using a LakeShore Model 7410 vibrating sample magnetometer (VSM).

Powders of melt-spun NdFeB were aged in hydrogen gas using a PARR high pressure vessel. For safety, a mixture of $2.8 \% \mathrm{H}_{2}$ gas in $\mathrm{Ar}$ (by volume) was used. Powder was placed into the high pressure vessel, sealed, evacuated to remove the air, and back-filled with 510 psig of the $\mathrm{H}_{2} / \mathrm{Ar}$ mixture, equivalent to an $\mathrm{H}_{2}$ partial pressure of $1 \mathrm{~atm}$. The vessel was periodically cooled, flushed, and a sample of powder removed for testing.

Chemical analyses were performed by inductively coupled plasma atomic emission spectrometery (ICP/AES) utilizing a Thermo IRIS Intrepid II XDL ICP-AES for boron and metals (except $\mathrm{Nb}$ ), by semi-quantitative $x$-ray fluorescence (XRF) utilizing a Thermo Perform'X WDXRF Spectrometer for $\mathrm{Nb}$, and by a LECO CS-844 Carbon/Sulfur Determinator for carbon and sulfur. The hydrogen contents of hydrogen-aged samples were directly measured by inert gas fusion using a LECO TCH600 Hydrogen Nitrogen and Oxygen Determinator. Crystal structure parameters, lattice expansion, and phase composition were determined from $\mathrm{x}$-ray diffraction (XRD) patterns using Rietveld powder diffraction fitting. XRD patterns were collected using copper $\mathrm{K}_{\alpha}$ radiation and Bragg-Brentano geometry with a Bruker D8 diffractometer. Powder morphology was examined by scanning electron microscopy (SEM) and the hard magnetic microstructure was examined by transmission electron microscopy (TEM). 


\section{RESULTS AND DISCUSSION}

Fig. 1 shows the magnetic performance of melt-spun NdFeB IM magnets using nylon binder after aging in ATF at $150{ }^{\circ} \mathrm{C}$ for times $\mathrm{t}=72,500$, and $1000 \mathrm{hr}$. Several magnets were measured at each aging time, giving the clusters of curves in the figure. The changes in intrinsic coercivity $\mathrm{H}_{\mathrm{ci}}$,

remanence $\mathrm{B}_{\mathrm{r}}$, and energy product $(\mathrm{BH})_{\max }$ are summarized in Table 1 relative to their starting values prior to aging. While there is little change in $B_{r}$ with ATF aging, a substantial loss of coercivity is evident; $\mathrm{H}_{\mathrm{ci}}$ has dropped by about $18 \%$ after $1000 \mathrm{hr}$.

Room temperature demagnetization curves of melt-spun NdFeB/nylon IM magnets aged in air or ATF are compared in Fig. 2. The room temperature demagnetization curves of the asreceived magnets prior to aging are shown in dark blue. After aging for $1000 \mathrm{hr}$ in ATF, the magnets show substantial loss (dark red). The air-aged magnets (dark green) have considerably less $\mathrm{H}_{\mathrm{ci}}$ loss (about 4\%) compared to the ATF-aged magnets. Air aging does produce slightly greater loss in magnetization than ATF aging, evident as the slightly lower second quadrant $M(H)$ seen in the air-aged samples in Fig. 2 , which indicates that air directly attacks the $\mathrm{Nd}_{2} \mathrm{Fe}_{14} \mathrm{~B}$ phase central to the excellent magnetic properties of $\mathrm{NdFeB}$, whereas ATF appears to mostly preserve the $\mathrm{Nd}_{2} \mathrm{Fe}_{14} \mathrm{~B}$ phase while degrading its ability to resist demagnetization.

Fig. 2 includes post-aging demagnetization curves measured at $160{ }^{\circ} \mathrm{C}$ for unaged IM magnets (light blue) and after air (light green) or ATF (red) aging for $1000 \mathrm{hr}$ at $150{ }^{\circ} \mathrm{C}$. The same qualitative difference between air and ATF aging showed up in the high temperature performance. Given the importance of the temperature dependence in traction motor applications, magnetic properties were measured at a series of elevated temperatures $\left(65^{\circ} \mathrm{C}, 100{ }^{\circ} \mathrm{C}, 140{ }^{\circ} \mathrm{C}\right.$, and 160 ${ }^{\circ} \mathrm{C}$ ). The relative aging losses of $\mathrm{H}_{\mathrm{ci}}$ and $\mathrm{B}_{\mathrm{r}}$, shown in Fig. 3, were virtually independent of measurement temperature within the scatter of the data for both ATF- and air-aged samples. These results confirmed that room temperature measurements were representative of the aging losses at all temperatures. Fig. 3 also graphically illustrates that $B_{r}$ is nearly insensitive to aging in either ATF or air, but that $\mathrm{H}_{\mathrm{ci}}$ is heavily degraded by aging in ATF. The loss of coercivity is therefore the focus of this work.

Relative room temperature aging losses in $\mathrm{H}_{\mathrm{ci}}$ are shown in Fig. 4 for several different IM or CM magnets. Each curve corresponds to magnets aged in either air (open symbols and dashed lines) or ATF (filled symbols and solid lines). Each data point is the average of the values obtained for several different samples from the same vendor. Except for the IM magnet using PPS binder, other combinations of IM/CM processing and binder choice have higher degradation rates when aged in ATF than when aged in air. 
To deconvolute the effects of binder and processing, we conducted aging tests using bare melt-spun NdFeB powder without binder. Fig. 5 compares aging of the bare powder in air (green) and ATF (red), clearly demonstrating that the additional aging was directly related to exposure to the ATF. Chemical analyses of the powder before and after aging are shown in Table 2. The powder chemistry is essentially unchanged during aging, showing that aging is not the result of a direct chemical reaction between ATF and NdFeB.

Because coercivity is highly microstructure-sensitive, the morphology and microstructure of aged powder flakes were examined by SEM and TEM. The SEM micrographs (Fig. 6) show no discernible difference between the powder particles before and after ATF aging. The TEM micrograph from the interior of a thinned particle (Fig. 7) revealed $50 \mathrm{~nm}$ diameter grains of $\mathrm{Nd}_{2} \mathrm{Fe}_{14} \mathrm{~B}$ phase, with $0.7 \mathrm{~nm}$ wide grain boundaries between. This microstructure is consistent with the known structure of melt-spun $\mathrm{NdFeB}$, and again there is no evidence for alteration of the NdFeB microstructure by aging.

X-ray diffraction analysis proved more revealing. Table 3 shows the crystal lattice parameters $a$ and $c$ and unit cell volume $V$ for the primary $\mathrm{Nd}_{2} \mathrm{Fe}_{14} \mathrm{~B}$ hard magnetic phase. The unit cell volume in the as-spun $\mathrm{NdFeB}$ powder (line 3 ) was slightly expanded by $0.11 \%$ compared to the $\mathrm{Nd}_{2} \mathrm{Fe}_{14} \mathrm{~B}$ reference standard [1]. In part this can be ascribed to stoichiometry and additives to the composition, however rapidly quenched materials frequently have slightly reduced density due to quenched-in defects in the atomic structure.

After aging in air for $2000 \mathrm{hr}$ at $150{ }^{\circ} \mathrm{C}$, there was little change in the unit cell volume; if anything, $\mathrm{V}$ decreased slightly, perhaps due to structural relaxation from the rapidly quenched state. Because XRD is surface sensitive, with a penetration depth of no more than $2 \mu \mathrm{m}$, the aged powder was ground to produce fresh surfaces representative of the structure deeper within the powder particles. The ground sample XRD was essentially identical to that of the unground powder.

Aging in ATF, however, produced additional expansion of the cell volume by $0.07 \%$, as shown in Table 3. After grinding, the same powder showed a considerable volume expansion of $0.19 \%$, indicating that the volume expansion extended deep within the particle interiors, and in fact was larger in the interior than at the surface. We conclude that the larger volume expansion observed for the ground sample is characteristic of the vast majority of the interior.

We ascribe the volume expansion during ATF aging to the incorporation of hydrogen dissociated from the organic liquid ATF into the melt-spun NdFeB powder. Hydrogen is known to diffuse into the $\mathrm{Nd}_{2} \mathrm{Fe}_{14} \mathrm{~B}$ crystal structure [2,3,4] and occupy interstitial sites to form the isomorphic hydride $\mathrm{Nd}_{2} \mathrm{Fe}_{14} \mathrm{BH}_{\mathrm{x}}$ with up to $\mathrm{x}=5 \mathrm{H}$ per formula unit. $\mathrm{The} \mathrm{Nd}_{2} \mathrm{Fe}_{14} \mathrm{~B}$ unit cell volume expands to 
accommodate the additional hydrogen at the rate of $1.1 \%$ per hydrogen $x$ for $x<3$ [5]. Incorporation of hydrogen also results in a dramatic decrease in the magnetic anisotropy field $\mathrm{H}_{\mathrm{a}}$ [6], which in turn reduces the coercivity $\mathrm{H}_{\mathrm{ci}}$. Previous hydriding studies found that inserting hydrogen in the range $2.7 \leq x \leq 4.9$ reduced $H_{a}$ from its hydrogen-free value of $\mu_{0} H_{a}=7.1-8.2$ Tesla [6] to about $\mu_{0} \mathrm{H}_{a}=1.7-2.0$ Tesla [7,8,9]. Consistent with those findings, Andreev et al. reported that the first-order anisotropy constant decreased from $K_{1}=4.9 \mathrm{MJ} / \mathrm{m}^{3}$ for $\mathrm{Nd}_{2} \mathrm{Fe}_{14} B$ to $\mathrm{K}_{1}$ $=0.79 \mathrm{MJ} / \mathrm{m}^{3}$ for $\mathrm{Nd}_{2} \mathrm{Fe}_{14} \mathrm{BH}_{3.8}$ [10]. The coercivity of melt-spun $\mathrm{Nd}_{2} \mathrm{Fe}_{14} \mathrm{~B}$ would be expected to scale similarly, thus hydrogen absorption is consistent with observed $\mathrm{H}_{\mathrm{ci}}$ loss in ATF.

To further test hydrogen as the probable aging agent in ATF, we aged melt-spun $\mathrm{NdFeB}$ powder in a mixture of $2.8 \%$ hydrogen gas in argon (without ATF) at 1 bar $\mathrm{H}_{2}$ partial pressure for 72,500 , and $2000 \mathrm{hr}$. Direct measurement of the post-aging hydrogen content by inert gas fusion confirmed significant hydrogen absorption by the powder, as shown in Fig. 8 and Table 4. As with ATF, aging in $\mathrm{H}_{2}$ expanded the crystal lattice (see Table 3) by an amount that reached $1.08 \%$ at $2000 \mathrm{hr}$. The demagnetization curves of $\mathrm{H}_{2}$-aged melt-spun $\mathrm{NdFeB}$, shown in Fig. 9, likewise degraded in a manner similar to, but more rapid than, that observed in ATF, as illustrated by the blue curve in Fig. 5. The effects of aging on the hard magnetic properties of melt-spun NdFeB are summarized in Table 4.

In Fig. 10 we plot the relative degradation of $\mathrm{H}_{\mathrm{ci}}$ as a function of the lattice expansion observed via XRD (blue curve). In order to connect the $\mathrm{H}_{2}$ results back to the ATF-aged materials, we include the data for melt-spun NdFeB aged for $2000 \mathrm{hr}$ in ATF for both the as-aged powder and the aged powder after grinding to better expose the powder particle interiors. The ground powder result correlates very well with the $\mathrm{H}_{2}$ aging data.

Two details are worth noting regarding the $\mathrm{H}_{2}$ aging results. First, the depressed magnetization in the second quadrant after aging for 2000 hours clearly indicates partial decomposition of the primary $\mathrm{Nd}_{2} \mathrm{Fe}_{14} \mathrm{~B}$ phase into at least one soft magnetic phase, whose contribution also accounts for the increase in first quadrant magnetization. This is consistent with XRD Rietveld analysis showing the growth of an Fe-like bcc phase (see Table 3). However, the two results are quantitatively inconsistent. XRD extracts an estimated phase composition of $32 \mathrm{wt} \%$ $\mathrm{Nd}_{2} \mathrm{Fe}_{14} \mathrm{~B}$ and $68 \%$ Fe-like bcc phase after $2000 \mathrm{hr}$; such a high content of soft magnetic phase would produce a much more drastic degradation of the second quadrant magnetization. Indeed, the content of Fe can be semiquantitatively estimated from the magnetization in the first quadrant. After $2000 \mathrm{hr}$ exposure to $\mathrm{H}_{2}, \mu_{0} \mathrm{M}(\mathrm{H})$ at positive $\mathrm{H}$ lies about $0.9 \mathrm{~T}$ higher than the original unaged curve. Attributing the difference to $\mathrm{Nd}_{2} \mathrm{Fe}_{14} \mathrm{~B}$ decomposition with $\mathrm{Fe}$ as the only magnetic decomposition product, then $\Delta \mu_{0} \mathrm{M}=\mathrm{f} \mu_{0} \mathrm{M}_{\mathrm{Fe}}-\mathrm{f} \mu_{0} \mathrm{M}_{\mathrm{Nd} 2 \mathrm{Fe} \text { 14B }}$. where $\mathrm{f}$ is the fraction of $\mathrm{Nd}_{2} \mathrm{Fe}_{14} \mathrm{~B}$ 
decomposed. Taking $\mu_{0} \mathrm{M}_{\mathrm{Nd} 2 \mathrm{Fe} 14 \mathrm{~B}}=\mu_{0} \mathrm{M}(\mathrm{H})$ of the unaged sample, and $\mu_{0} \mathrm{M}_{\mathrm{Fe}}=\mu_{0} \mathrm{M}_{\mathrm{Fe}}=2.15 \mathrm{~T}(\mathrm{Fe}$ is magnetically soft, so it will reach its saturation value $\mu_{0} \mathrm{M}_{\mathrm{s}}$ at low field), we estimate that the Fe content is only $\sim 10 \%$. The discrepancy arises from the nature of the two measurements; as previously stated, XRD samples only the outer $2 \mu \mathrm{m}$ of the powder particles, where the decomposition is severe, while magnetization is a bulk measurement of the entire sample. This finding can be extended to the powder samples aged in ATF: while the mechanism for having higher hydrogen content (larger lattice expansion) in the interior compared to the surface is not certain at this point, it seems likely that the hydrogen-induced $\mathrm{Nd}_{2} \mathrm{Fe}_{14} \mathrm{~B}$ decomposition at the surface depletes the hydrogen from $\mathrm{Nd}_{2} \mathrm{Fe}_{14} \mathrm{BH}_{\mathrm{x}}$ in the surface layer.

Second, the measured hydrogen content is higher than that inferred from the crystallographic lattice expansion. For example, after $2000 \mathrm{hr}$ the hydrogen content is $0.29 \mathrm{wt} \%$, corresponding to $\mathrm{x}$ $=3.2$; if all of the hydrogen went into the $\mathrm{Nd}_{2} \mathrm{Fe}_{14} \mathrm{~B}$ phase, this should have produced a lattice expansion of $3.5 \%$, whereas the observed expansion is only $1.08 \%$. Clearly only part of the hydrogen is going into the $\mathrm{Nd}_{2} \mathrm{Fe}_{14} \mathrm{~B}$ phase, and we infer that the remainder is captured in the decomposition products on the outer surface of the powder particles. That direct evidence of hydrides is not apparent in the XRD patterns suggests that the hydrides may be heavily disordered.

\section{SUMMARY}

Anomalously large degradation of hard magnetic properties was observed during aging of injection molded melt-spun NdFeB magnets in automatic transmission fluid at $150{ }^{\circ} \mathrm{C}$. Chemical analysis and electron micrographic studies indicated that aging did not arise from a direct reaction between carbon or sulfur from the ATF and the NdFeB magnetic material. Aging of bare powders further confirmed that reaction with the binder did not play a dominant role in the aging behavior. Modest but significant crystallographic expansion of the $\mathrm{Nd}_{2} \mathrm{Fe}_{14} \mathrm{~B}$ lattice was observed in the aged powders, similar to the expansion observed when hydrogen atoms are inserted into interstitial sites in the $\mathrm{Nd}_{2} \mathrm{Fe}_{14} \mathrm{~B}$ crystal structure. Aging experiments conducted in $\mathrm{H}_{2}$ gas without ATF gave similar, but greatly amplified, aging behavior and lattice expansion. While some ( 10\%) degradation of the primary $\mathrm{Nd}_{2} \mathrm{Fe}_{14} \mathrm{~B}$ phase does occur during aging in $\mathrm{H}_{2}$, the degradation of coercivity $\mathrm{H}_{\mathrm{ci}}$ correlates with the lattice expansion. We conclude that the probable dominant aging mechanism is hydrogen dissociated from the ATF at $150{ }^{\circ} \mathrm{C}$ that enters the $\mathrm{Nd}_{2} \mathrm{Fe}_{14} \mathrm{~B}$ lattice. The consequent lattice expansion severely degrades the anisotropy field $\mathrm{H}_{\mathrm{a}}$ of $\mathrm{Nd}_{2} \mathrm{Fe}_{14} \mathrm{~B}$, which in turn reduces the coercivity. The physical mechanism that dissociates hydrogen from ATF is not currently known. 
Hydrogen could be dissociated from the ATF at the surface of the powder particles, and subsequently diffused into the $\mathrm{Nd}_{2} \mathrm{Fe}_{14} \mathrm{~B}$ phase in the particle interior. For example, the thermodynamically unfavorable dehydrogenation reaction of propan-2-ol to acetone becomes thermodynamically allowed in the presence of the rare-earth-transition-metal compounds $\mathrm{Nd}_{2} \mathrm{Co}_{7}$ and $\mathrm{Sm}_{2} \mathrm{Co}_{7}$ because their reversible absorption of large quantities of hydrogen modifies the reaction energies [11]. Alternatively, ATF at $150{ }^{\circ} \mathrm{C}$ may generate a small $\mathrm{H}_{2}$ vapor pressure that directly infuses $\mathrm{Nd}_{2} \mathrm{Fe}_{14} \mathrm{~B}$.

\section{ACKNOWLEDGMENTS}

The authors would like to thank Andrew Zabik and Patrick Hanley of the Warren Materials Laboratory. This work was supported in part by the US Department of Energy grant GA21GG8P.92-Injection Molded Magnets. 


\section{REFERENCES}

1. ICDD database $2014 \mathrm{Nd}_{2} \mathrm{Fe}_{14} \mathrm{~B}$ diffraction pattern 04-006-8963.

2. V. A. Yartys, A. J. Williams, K. G. Knoch, P. J. McGuiness, and I. R. Harris, J. Alloys Compds. 239, 50 (1996).

3. O. Gutfleisch and I. R. Harris, J. Phys. D: Appl. Phys. 29, 2255 (1996).

4. J. J. Luo, P. de Rango, D. Fruchart, J. N. Mei, and L. Zhou, J. Alloys Compds. 509, 4252 (2011).

5. O. Isnard, W. B. Yelon, S. Miraglia, and D. Fruchart, J. Appl. Phys. 78, 1892 (1995).

6. J. F. Herbst, Rev. Mod. Phys. 63, 819 (1991).

7. K. Oesterreicher and H. Oesterreicher, Phys. Stat. Sol. (a) 85, K61 (1984).

8. L Pareti, O. Moze, D. Fruchart, Ph. L'Heritier, and A. Yaouanc, J. Less-Common Met. 142, 187 (1988).

9. W. E. Wallace, F. Pourarian, A. T. Pedziwiatr, and E. B. Boltich, J. Less-Common Met. 130, 33 (1987).

10, A. V. Andreev, A. V. Deryagin, N. V. Kudrevatykh, N. V. Mushnikov, V. A. Reĭmer, and S. V. Terent'ev, Sov. Phys. JETP 63, 608 (1986).

11. H. Imamura, K. Yamada, K. Nukui, and S. Tsuchiya, J. Chem. Soc., Chem. Commun. Iss. 4, 367 (1986). 
Table 1: Magnetic properties of melt-spun NdFeB jnjection molded magnets using nylon binder. The upper section of the table gives the initial unaged values of the intrinsic coercivity $\mathrm{H}_{\mathrm{ci}}$, the remanence $B_{r}$, and the energy product $(B H)_{\max }$, while the remainder of the table shows the relative change in those properties as a function of aging time in either ATF or air.

\begin{tabular}{|l|c|c|c|c|c|c|}
\hline & \multicolumn{2}{c|}{$\begin{array}{c}\mathrm{H}_{\mathrm{ci}} \\
(\mathrm{kA} / \mathrm{m})\end{array}$} & \multicolumn{2}{c|}{$\begin{array}{c}\mathrm{B}_{\mathrm{r}} \\
(\mathrm{T})\end{array}$} & \multicolumn{2}{c|}{$\begin{array}{c}(\mathrm{BM})_{\max } \\
\mathrm{kJ} / \mathrm{m}^{3}\end{array}$} \\
\hline $\begin{array}{l}\text { Initial } \\
\text { values }\end{array}$ & \multicolumn{2}{|c|}{959} & \multicolumn{2}{c|}{0.509} & \multicolumn{2}{c|}{45.6} \\
\hline & \multicolumn{2}{|c|}{$\mathrm{H}_{\mathrm{ci}} / \mathrm{H}_{\mathrm{ci}}(0)$} & \multicolumn{2}{c|}{$\mathrm{B}_{\mathrm{r}} / \mathrm{B}_{\mathrm{r}}(0)$} & \multicolumn{2}{c|}{$\begin{array}{c}(\mathrm{BH})_{\max } / \\
(\mathrm{BH})_{\max }(0)\end{array}$} \\
\hline & ATF & Air & ATF & Air & ATF & Air \\
\hline 0 & 1 & 1 & 1 & 1 & 1 & 1 \\
\hline 72 & 0.974 & 0.982 & 0.994 & 0.998 & 0.983 & 0.983 \\
\hline 500 & 0.884 & 0.958 & 0.989 & 0.981 & 0.935 & 0.914 \\
\hline 1000 & 0.830 & 0.963 & 0.981 & 0.979 & 0.929 & 0.903 \\
\hline
\end{tabular}


Table 2: Chemical analysis of melt-spun NdFeB powder before and after aging for $2000 \mathrm{hr}$ at 150 ${ }^{\circ} \mathrm{C}$ in either air or ATF. All values are given in wt\%. ICP analysis found that $\mathrm{Co}, \mathrm{Cu}, \mathrm{Ga}$, and $\mathrm{Zr}$ were all less than $0.1 \mathrm{wt} \%$.

\begin{tabular}{|l|c|c|c|c|c|c|c|c|c|c|}
\hline & $\begin{array}{c}\text { Al } \\
(\text { ICP) }\end{array}$ & $\begin{array}{c}\text { B } \\
(\text { ICP) }\end{array}$ & $\begin{array}{c}\text { Dy } \\
(\text { ICP) }\end{array}$ & $\begin{array}{c}\text { Nb } \\
(\mathbf{X R F})\end{array}$ & $\begin{array}{c}\text { Nd } \\
\text { (ICP) }\end{array}$ & $\begin{array}{c}\text { Pr } \\
(\text { ICP) }\end{array}$ & $\begin{array}{c}\text { Tb } \\
\text { (ICP) }\end{array}$ & $\begin{array}{c}\text { C } \\
\text { (LECO) }\end{array}$ & $\begin{array}{c}\text { S } \\
\text { (LECO) }\end{array}$ & $\begin{array}{c}\text { Fe } \\
\text { (ICP) }\end{array}$ \\
\hline Unaged & 0.2 & 1 & $<0.1$ & 2.3 & 25.9 & $<0.1$ & $<0.1$ & 0.020 & 0.0017 & Bal. \\
\hline ATF & 0.1 & 0.9 & 0.1 & 5.4 & 24.7 & 0.4 & $<0.1$ & 0.028 & 0.0019 & 68.5 \\
\hline Air & 0.2 & 0.9 & 0.1 & 5.1 & 24.9 & 0.4 & $<0.1$ & 0.028 & 0.0012 & 68.5 \\
\hline
\end{tabular}


Table 3: X-ray diffraction results on melt-spun NdFeB powder after aging in air, ATF, or $\mathrm{H}_{2}$ gas.

\begin{tabular}{|c|c|c|c|c|c|c|c|c|c|c|}
\hline \multirow{2}{*}{ Sample } & \multirow{2}{*}{$\begin{array}{l}\text { Aging } \\
\text { Agent }\end{array}$} & \multirow{2}{*}{$\begin{array}{l}\text { Aging } \\
\text { time } \\
\text { (hr) }\end{array}$} & \multicolumn{2}{|c|}{ Lattice parameters } & \multirow{2}{*}{$\begin{array}{l}\mathrm{Nd}_{2} \mathrm{Fe}_{14} \mathrm{~B} \\
\text { Cell Volume } \\
\qquad\left(\AA^{3}\right)\end{array}$} & \multirow{2}{*}{$\begin{array}{c}\mathrm{Nd}_{2} \mathrm{Fe}_{14} \mathrm{~B} \\
\Delta \mathrm{V} \\
(\%)\end{array}$} & \multirow{2}{*}{$\begin{array}{c}\mathrm{Fe} \\
\text { Cell Volume } \\
\left(\AA^{3}\right)\end{array}$} & \multirow{2}{*}{$\begin{array}{l}\mathrm{Fe} \\
\Delta \mathrm{V} \\
(\%)\end{array}$} & \multirow{2}{*}{$\begin{array}{c}\mathrm{Nd}_{2} \mathrm{Fe}_{14} \mathrm{~B} \\
\text { content } \\
\text { (wt } \%)\end{array}$} & \multirow{2}{*}{$\begin{array}{c}\text { Fe } \\
\text { content } \\
(w t \%)\end{array}$} \\
\hline & & & $\begin{array}{c}\mathrm{a} \\
(\AA)\end{array}$ & $\begin{array}{c}C \\
(\AA)\end{array}$ & & & & & & \\
\hline $\mathrm{Nd}_{2} \mathrm{Fe}_{14} \mathrm{~B}$ ref. & & & 8.804 & 12.205 & 946.01 & & & & & \\
\hline Fe ref. & & & 2.866 & & & & 23.541 & & & \\
\hline MS NdFeB & & 0 & 8.806 & 12.213 & 947.06 & & 24.414 & & 89 & 11 \\
\hline MS NdFeB & Air & 2000 & 8.804 & 12.212 & 946.56 & -0.05 & \multicolumn{4}{|c|}{ Not analyzed } \\
\hline $\begin{array}{l}\text { MS NdFeB } \\
\text { (ground) }\end{array}$ & Air & 2000 & 8.804 & 12.212 & 946.56 & -0.05 & \multicolumn{4}{|c|}{ Not analyzed } \\
\hline MS NdFeB & ATF & 2000 & 8.808 & 12.216 & 947.73 & 0.07 & \multicolumn{4}{|c|}{ Not analyzed } \\
\hline $\begin{array}{l}\text { MS NdFeB } \\
\text { (ground) }\end{array}$ & ATF & 2000 & 8.812 & 12.220 & 948.90 & 0.19 & \multicolumn{4}{|c|}{ Not analyzed } \\
\hline MS NdFeB & $\mathrm{H}_{2}$ & 72 & 8.809 & 12.215 & 947.87 & 0.09 & 24.617 & 0.83 & 76 & 24 \\
\hline MS NdFeB & $\mathrm{H}_{2}$ & 500 & 8.824 & 12.232 & 952.42 & 0.57 & 24.364 & -0.20 & 55 & 45 \\
\hline MS NdFeB & $\mathrm{H}_{2}$ & 2000 & 8.839 & 12.252 & 957.22 & 1.08 & 24.313 & -0.41 & 32 & 68 \\
\hline
\end{tabular}


Table 4: Hydrogen content and magnetic properties intrinsic coercivity $\mathrm{H}_{c i}$, inductive coercivity $\mathrm{H}_{\mathrm{c}}$, remanence $\mathrm{B}_{r}$, and energy product $(\mathrm{BH})_{\max }$ of $\mathrm{H}_{2}$-aged melt-spun NdFeB powder.

\begin{tabular}{|l|c|c|c|c|c|c|}
\hline \multicolumn{1}{|c|}{ Sample } & $\begin{array}{c}\text { Aging } \\
\text { time } \\
(\mathrm{hr})\end{array}$ & $\begin{array}{c}\text { Hydrogen } \\
\text { content } \\
(\mathrm{wt} \%)\end{array}$ & $\begin{array}{c}\mathrm{H}_{\mathrm{ci}} \\
(\mathrm{kA} / \mathrm{m})\end{array}$ & $\begin{array}{c}\mathrm{H}_{\mathrm{c}} \\
(\mathrm{kA} / \mathrm{m})\end{array}$ & $\begin{array}{c}\mathrm{B}_{\mathrm{r}} \\
(\mathrm{T})\end{array}$ & $\begin{array}{c}(\mathrm{BH})_{\max } \\
\left(\mathrm{kJ} / \mathrm{m}^{3}\right) \\
{[\mathrm{MGO}]}\end{array}$ \\
\hline MS NdFeB & 0 & 0.003 & 976 & 552 & 0.87 & $121[15.1]$ \\
\hline MS NdFeB & 72 & 0.046 & 922 & 561 & 0.87 & $123[15.5]$ \\
\hline MS NdFeB & 500 & 0.190 & 671 & 481 & 0.86 & $110[13.9]$ \\
\hline MS NdFeB & 2000 & 0.295 & 519 & 375 & 0.81 & $81[10.1]$ \\
\hline
\end{tabular}




\section{Figure Captions}

Fig. 1. Room temperature second quadrant demagnetization curves for injection molded meltspun (MS) NdFeB magnets in nylon at room temperature before aging (blue solid curve) and after aging in ATF at $150{ }^{\circ} \mathrm{C}$ for $72 \mathrm{hrs}$ (brown dashed), $500 \mathrm{hrs}$ (purple dash-dot), and $1000 \mathrm{hrs}$ (red dash-dot-dot).

Fig. 2. Second quadrant demagnetization curves for injection molded melt-spun (MS) NdFeB magnets in nylon before aging (blue solid curve) and after aging for $1000 \mathrm{hr}$ at $150{ }^{\circ} \mathrm{C}$ in either air (green dash-dot-dot) or ATF (red dashed). The three sets of curves on the left were measured at room temperature, while the three sets of curves on the right were measured at $160^{\circ} \mathrm{C}$.

Fig. 3. Relative change in remanence $B_{r}$ (blue square symbols) and coercivity $H_{c i}$ (red round symbols) for IM magnets molded in nylon after aging for 1000 hours in ATF (filled symbols, solid lines) or air (open symbols, dashed lines). The lines connect the averages of several samples. Each data point is the value obtained for the 1000 hour aged sample at the given measurement temperature ( $x$ axis) relative to the value for that sample prior to aging measured at the same temperature.

Fig. 4. Relative degradation of several different bonded melt-spun NdFeB magnets aged at 150 ${ }^{\circ} \mathrm{C}$ in air (open symbols, dashed lines) or in ATF (closed symbols, solid lines). Red: IM in nylon; blue: IM in PPS, molding company 1; green: IM in PPS, molding company 2; purple: CM in Epon Epoxy.

Fig. 5. Relative loss of $\mathrm{H}_{\mathrm{ci}}$ as functions of aging time at $150{ }^{\circ} \mathrm{C}$ in air (green open circles), ATF (red filled circles), or $\mathrm{H}_{2}$ gas (blue filled squares).

Fig. 6. Scanning electron micrographs of melt-spun NdFeB powder particles (a) before and (b) after aging in ATF for $2000 \mathrm{hr}$ at $150^{\circ} \mathrm{C}$.

Fig. 7. TEM image of NdFeB grains (upper) and grain boundaries (lower) in melt-spun NdFeB powder particles.

Fig. 8. Hydrogen content in $\mathrm{H}_{2}$-aged melt-spun $\mathrm{NdFeB}$ as a function of aging time.

Fig. 9. (a) Demagnetization curves and (b) $\mathrm{B}(\mathrm{H})$ curves for melt-spun NdFeB aged in 1 bar $\mathrm{H}_{2}$ gas at $150{ }^{\circ} \mathrm{C}$.

Fig. 10. Relative loss of coercivity $\mathrm{H}_{c i}$ as a function of crystal lattice volume expansion during aging of melt-spun $\mathrm{NdFeB}$ in hydrogen (blue curve). For comparison, the corresponding points for melt-spun NdFeB aged in ATF for $2000 \mathrm{hr}$ are shown, either as-aged (left point) or after grinding (right point). The ground ATF-aged sample, characteristic of the powder particle interior, agrees well with the $\mathrm{H}_{2}$-aged behavior. 


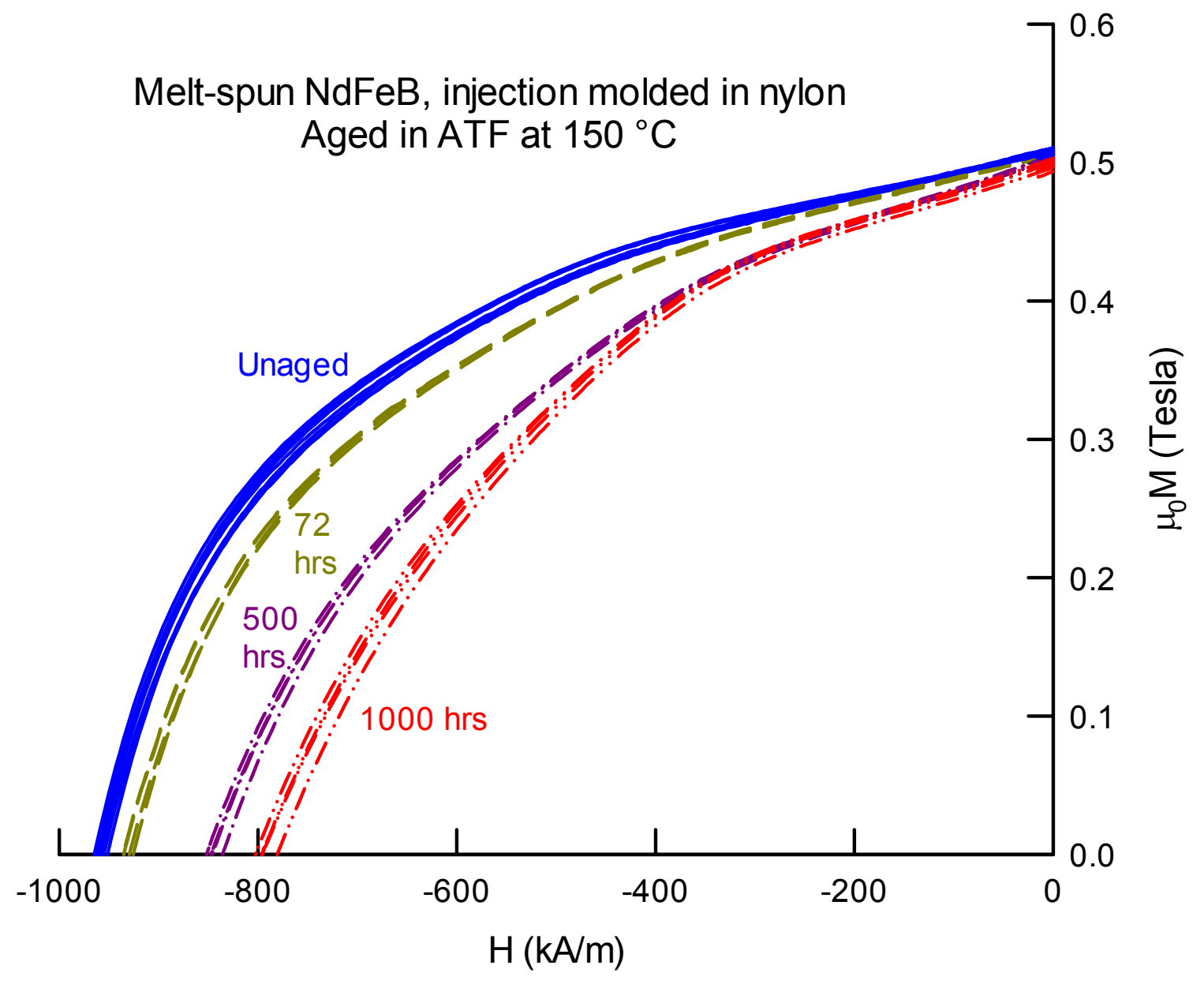

Fig. 1. Room temperature second quadrant demagnetization curves for injection molded melt-spun (MS) NdFeB magnets in nylon at room temperature before aging (blue solid curve) and after aging in ATF at $150{ }^{\circ} \mathrm{C}$ for $72 \mathrm{hrs}$ (brown dashed), $500 \mathrm{hrs}$ (purple dash-dot), and $1000 \mathrm{hrs}$ (red dashdot-dot). 


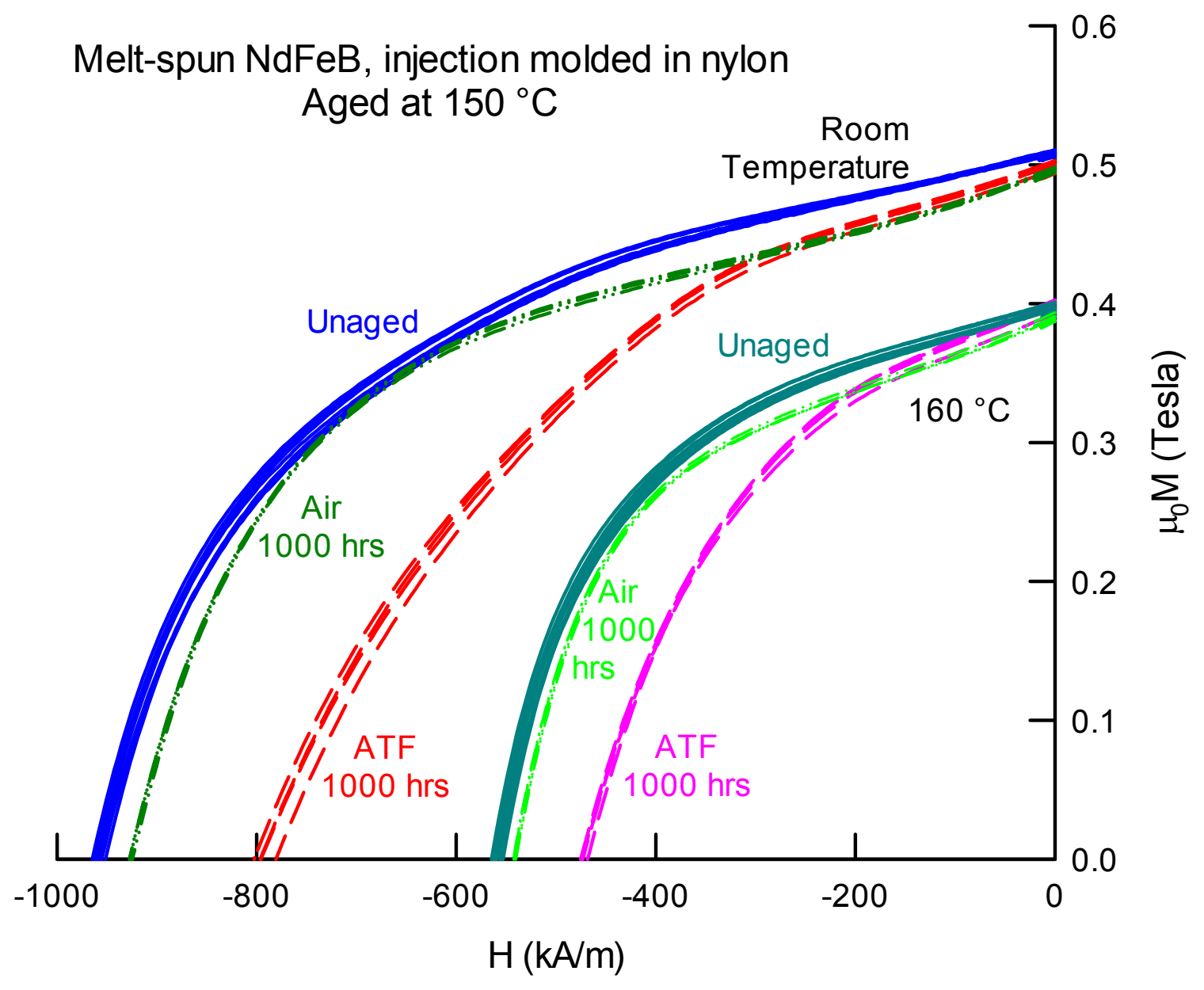

Fig. 2. Second quadrant demagnetization curves for injection molded melt-spun (MS) NdFeB magnets in nylon before aging (blue solid curve) and after aging for $1000 \mathrm{hr}$ at $150{ }^{\circ} \mathrm{C}$ in either air (green dash-dot-dot) or ATF (red dashed). The three sets of curves on the left were measured at room temperature, while the three sets of curves on the right were measured at $160{ }^{\circ} \mathrm{C}$. 


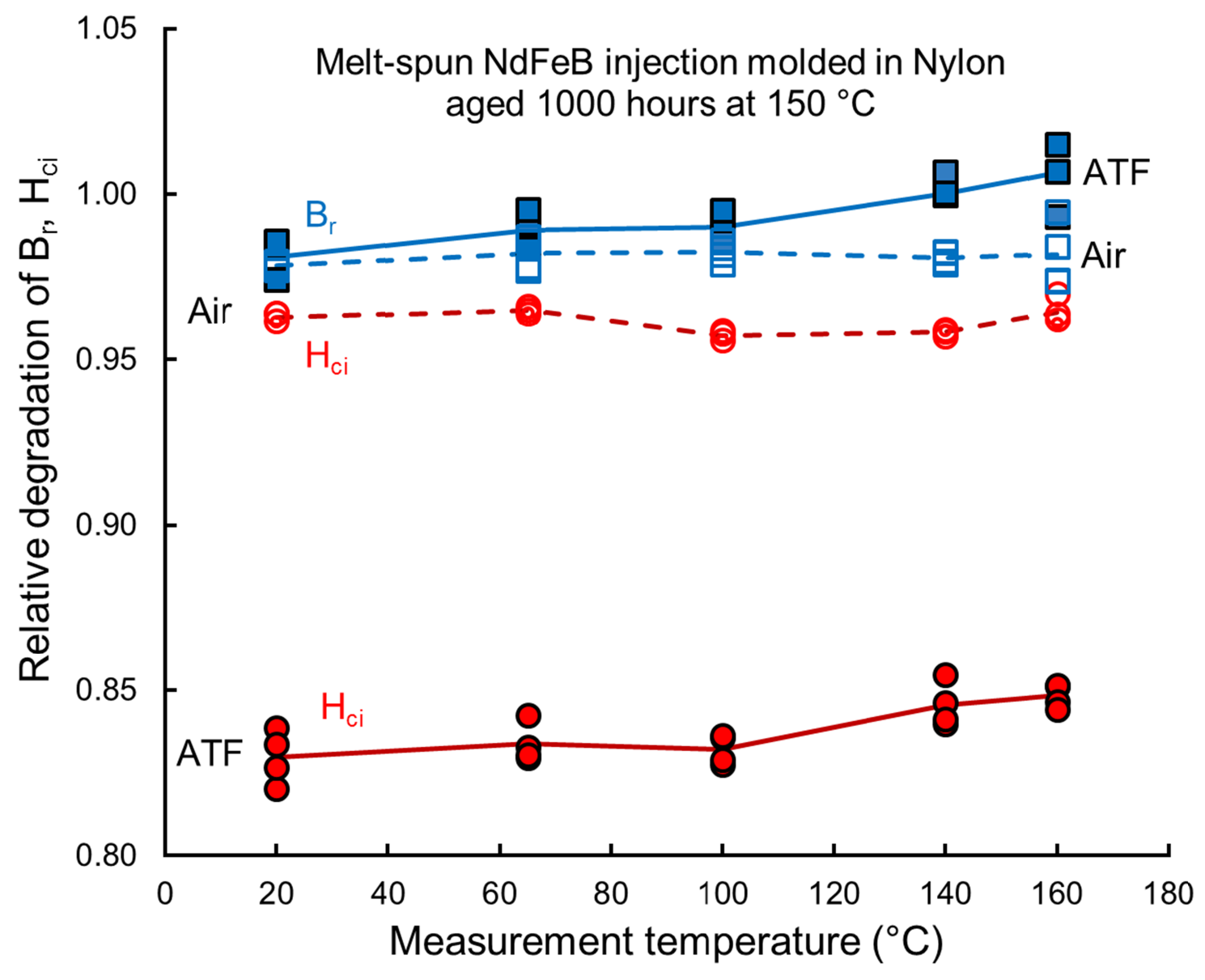

Fig. 3. Relative change in remanence $B_{r}$ (blue square symbols) and coercivity $H_{c i}$ (red round symbols) for IM magnets molded in nylon after aging for 1000 hours in ATF (filled symbols, solid lines) or air (open symbols, dashed lines). The lines connect the averages of several samples. Each data point is the value obtained for the 1000 hour aged sample at the given measurement temperature ( $x$ axis) relative to the value for that sample prior to aging measured at the same temperature. 


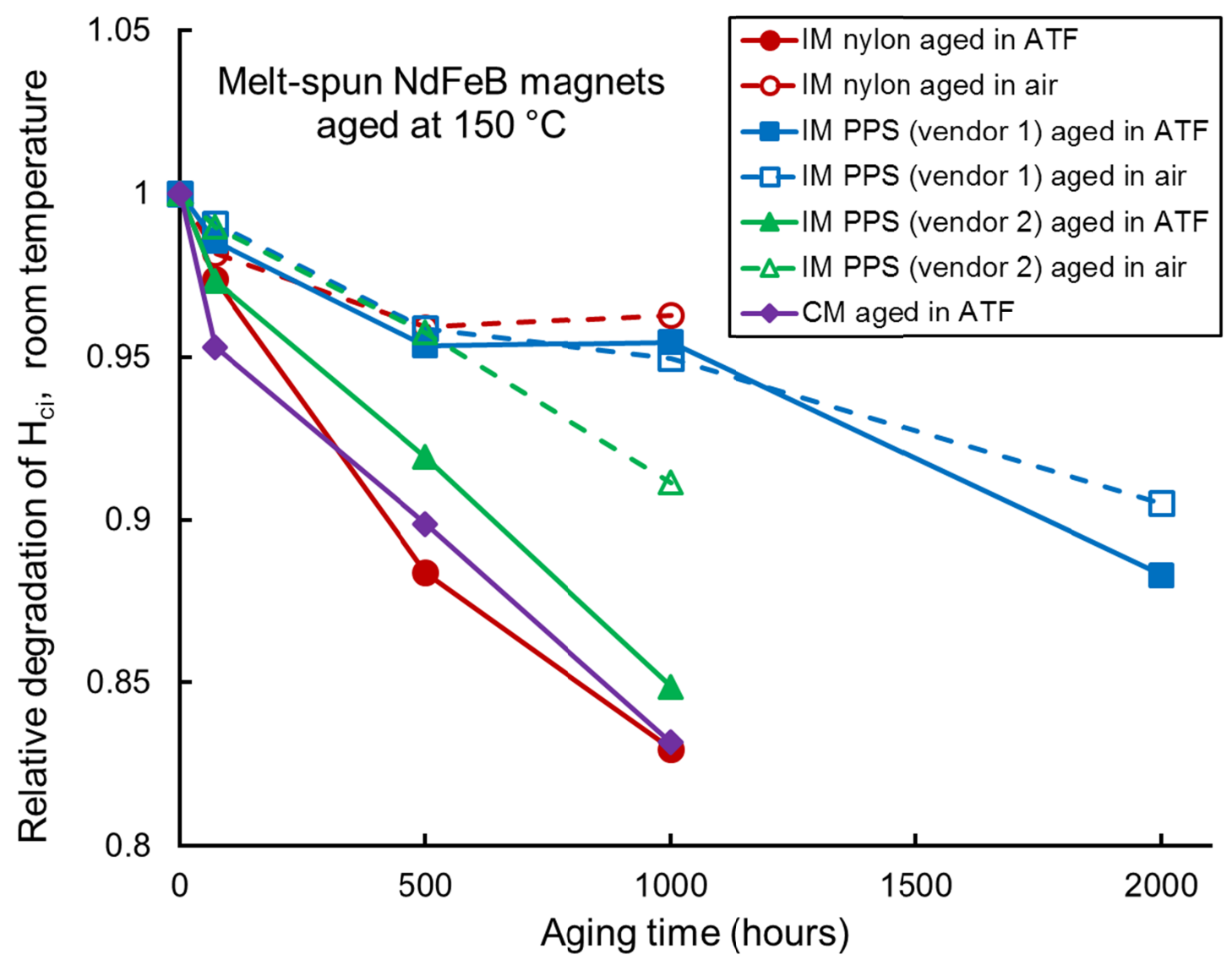

Fig. 4. Relative degradation of several different bonded melt-spun NdFeB magnets aged at $150{ }^{\circ} \mathrm{C}$ in air (open symbols, dashed lines) or in ATF (closed symbols, solid lines). Red: IM in nylon; blue: IM in PPS, molding company 1; green: IM in PPS, molding company 2; purple: CM in Epon Epoxy. 


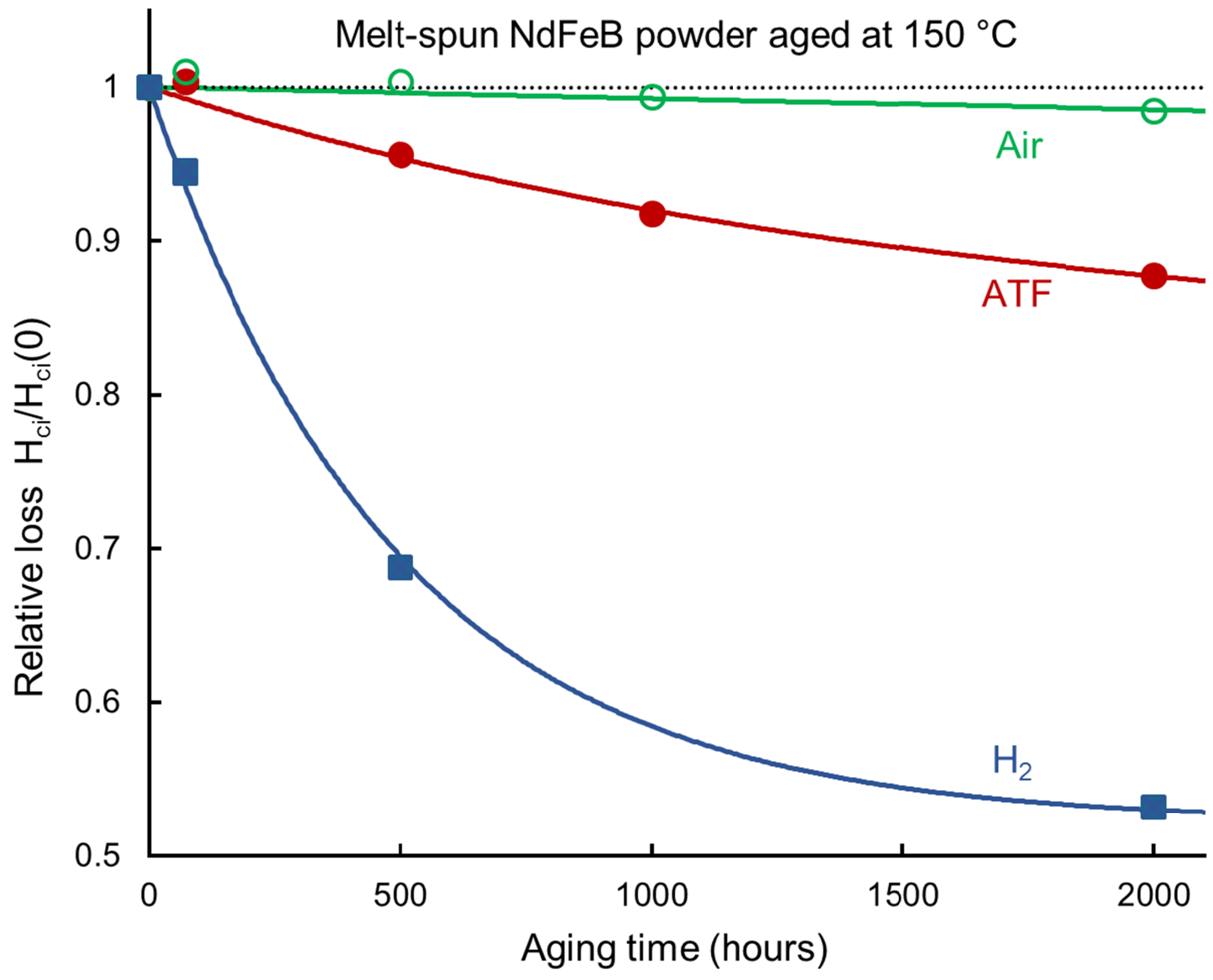

Fig. 5. Relative loss of $\mathrm{H}_{\text {ci }}$ as functions of aging time at $150{ }^{\circ} \mathrm{C}$ in air (green open circles), ATF (red filled circles), or $\mathrm{H}_{2}$ gas (blue filled squares). 

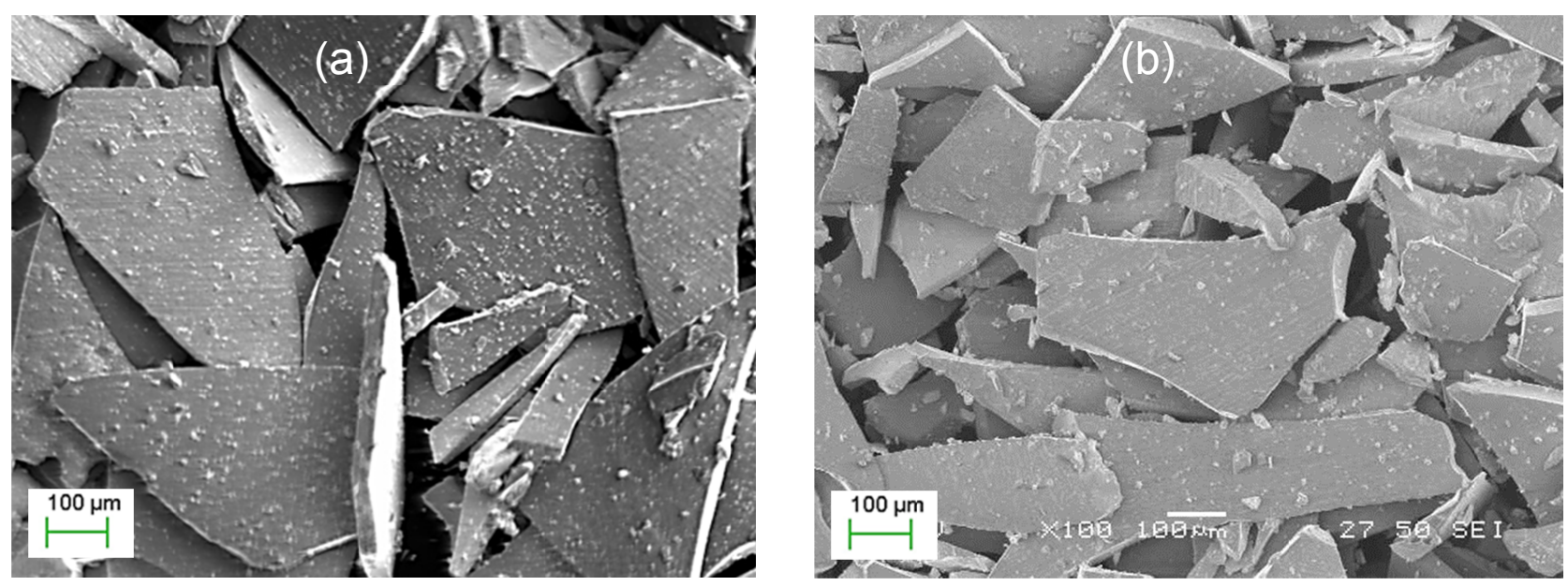

Fig. 6. Scanning electron micrographs of melt-spun NdFeB powder particles (a) before and (b) after aging in ATF for $2000 \mathrm{hr}$ at $150^{\circ} \mathrm{C}$. 

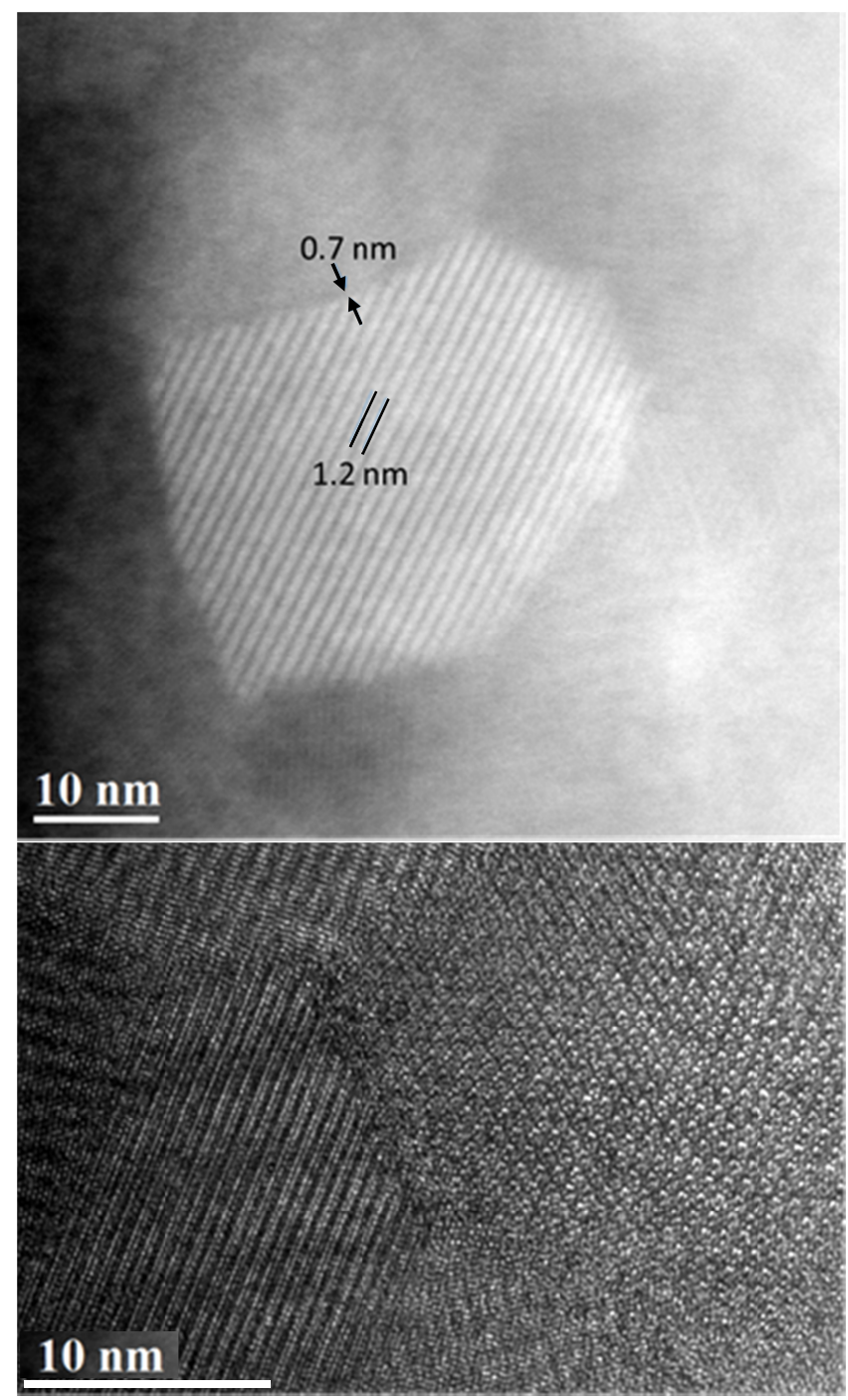

Fig. 7. TEM image of NdFeB grains (upper) and grain boundaries (lower) in melt-spun NdFeB powder particles. 


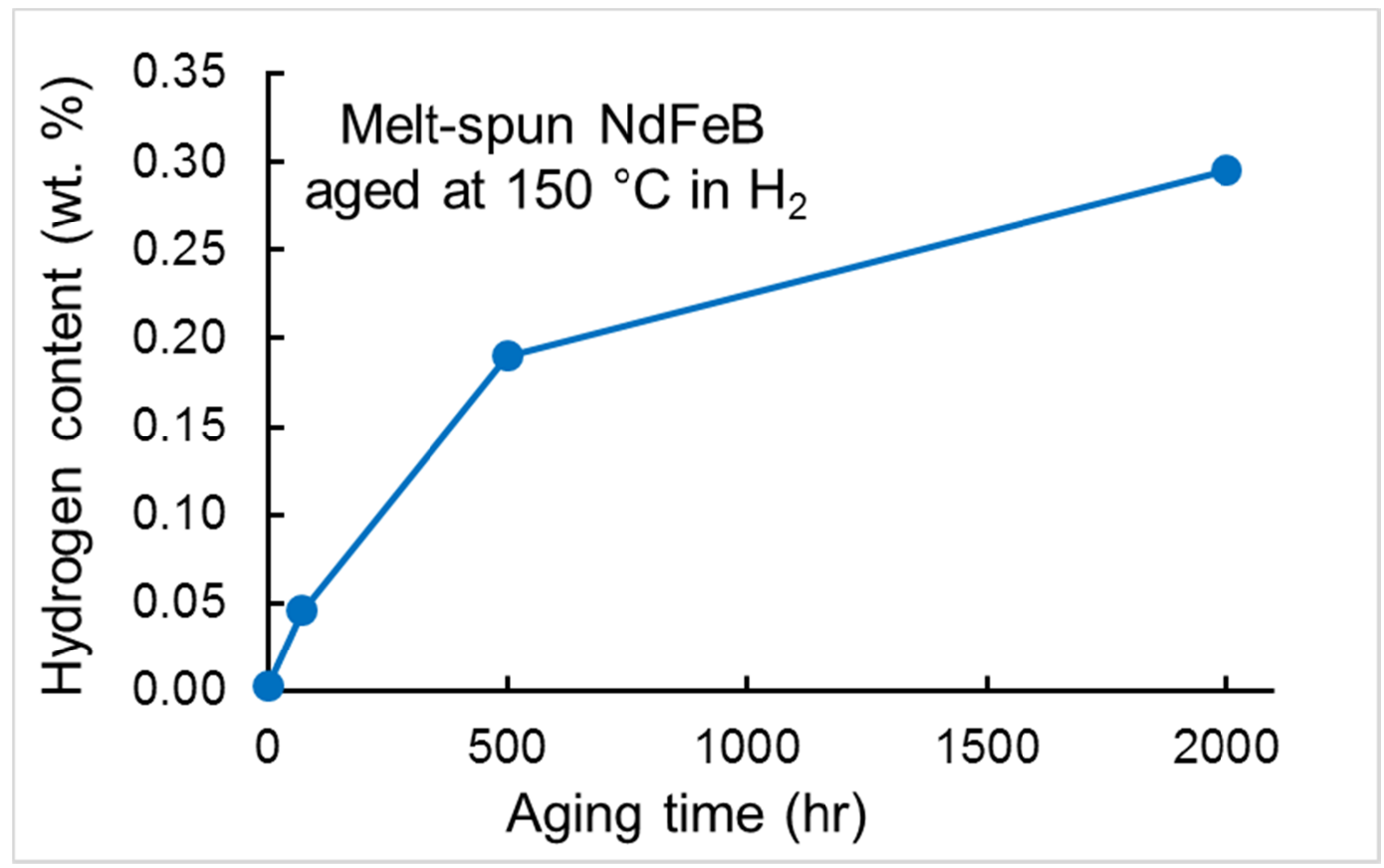

Fig. 8. Hydrogen content in $\mathrm{H}_{2}$-aged melt-spun $\mathrm{NdFeB}$ as a function of aging time. 


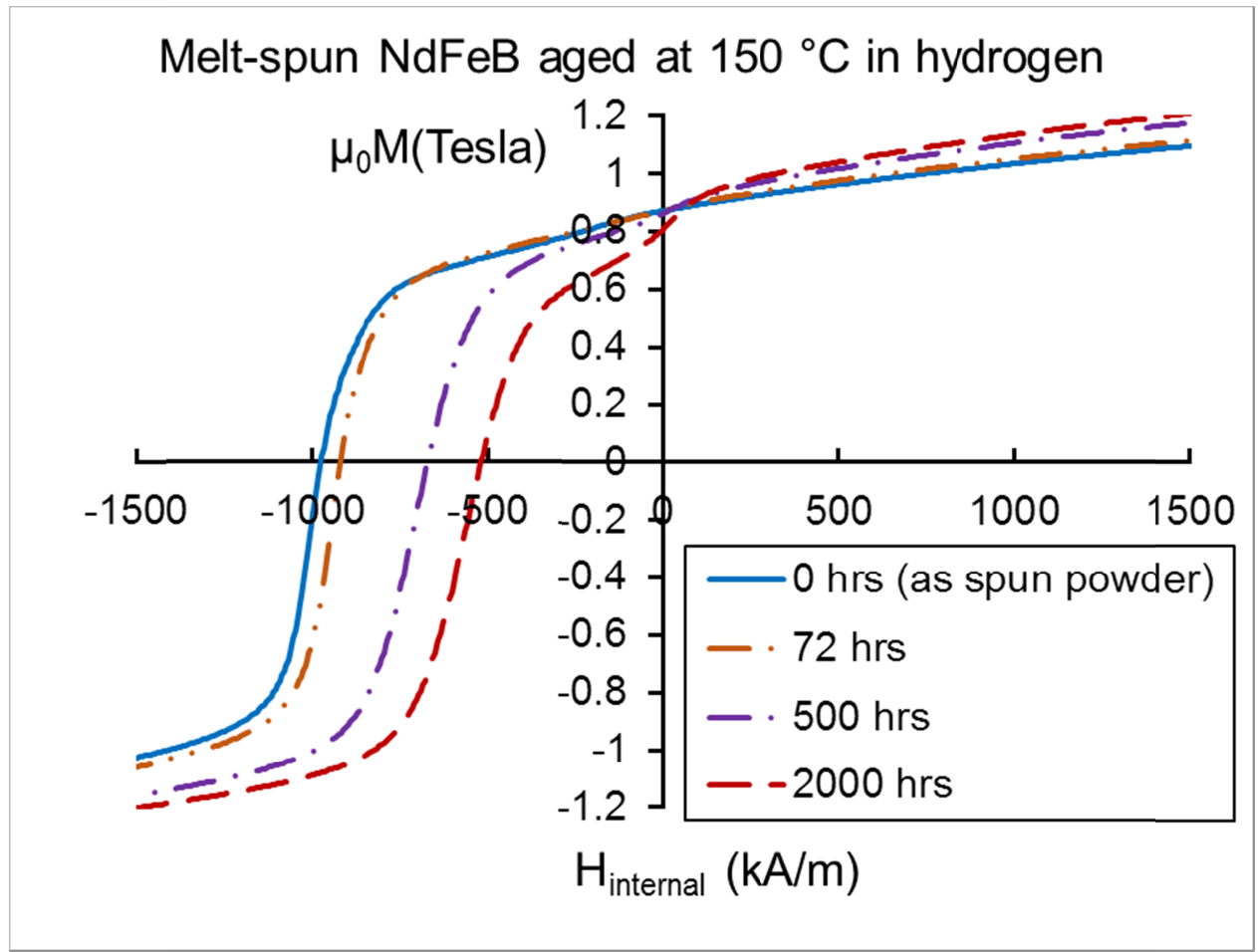

(a)

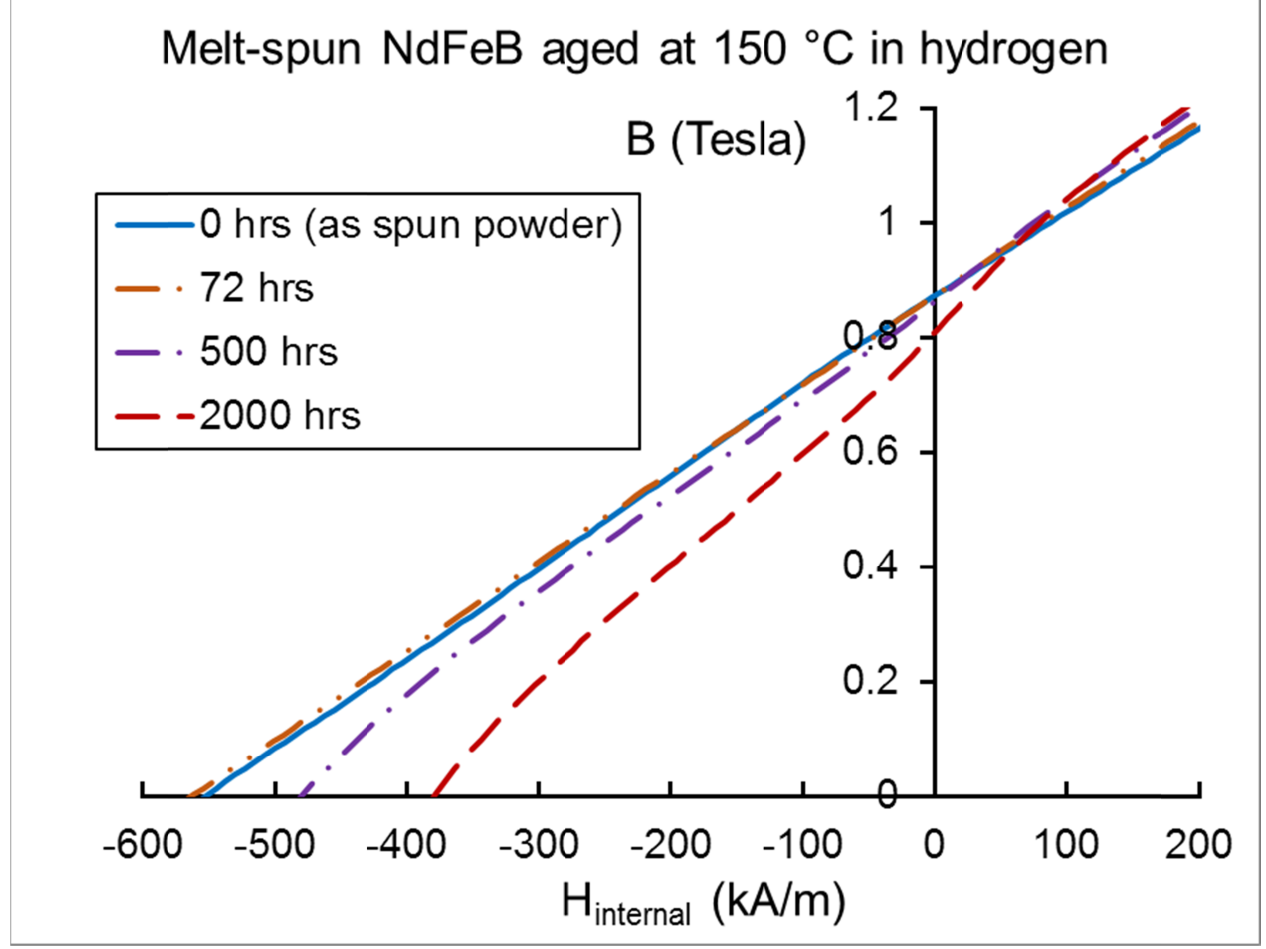

(b)

Fig. 9. (a) Demagnetization curves and (b) $\mathrm{B}(\mathrm{H})$ curves for melt-spun NdFeB aged in 1 bar $\mathrm{H}_{2}$ gas at $150{ }^{\circ} \mathrm{C}$. 


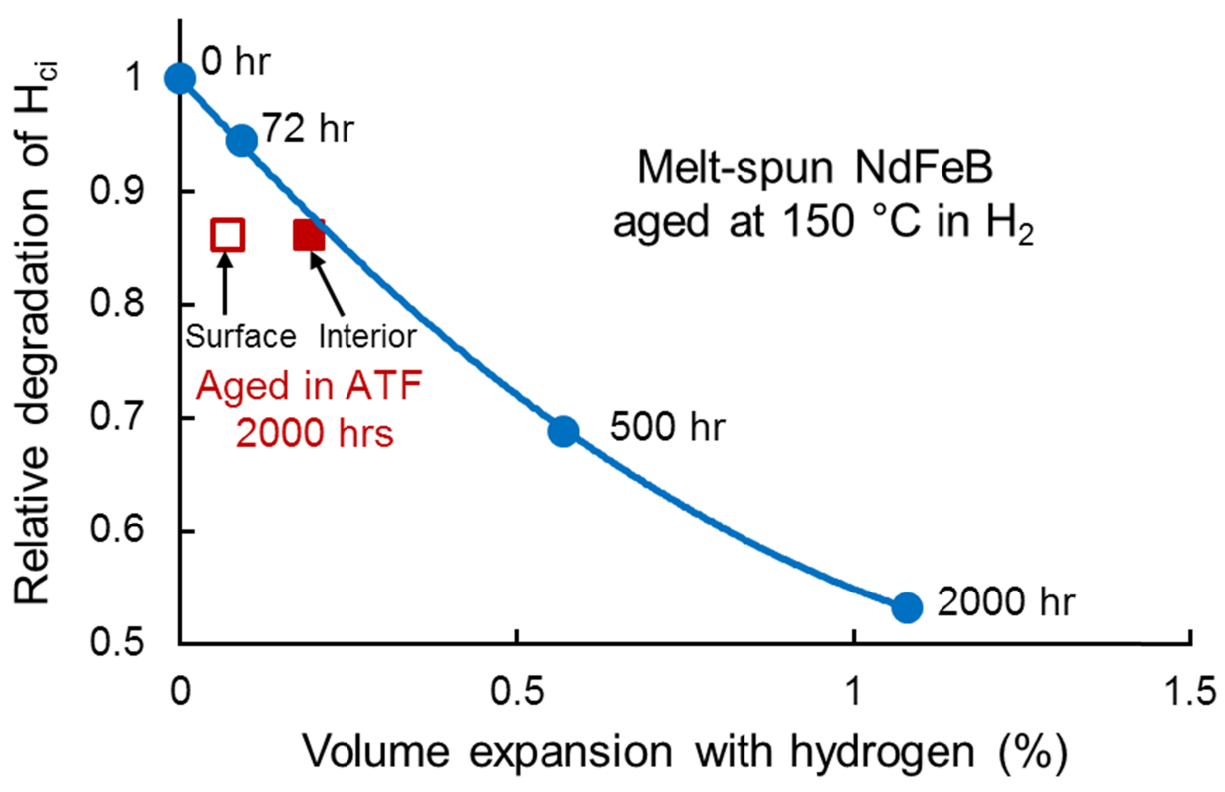

Fig. 10. Relative loss of coercivity $\mathrm{H}_{\mathrm{ci}}$ as a function of crystal lattice volume expansion during aging of melt-spun NdFeB in hydrogen (blue curve). For comparison, the corresponding points for meltspun NdFeB aged in ATF for $2000 \mathrm{hr}$ are shown, either as-aged (left point) or after grinding (right point). The ground ATF-aged sample, characteristic of the powder particle interior, agrees well with the $\mathrm{H}_{2}$-aged behavior. 